\title{
Escherichia coli expression and purification of LL37 fused to a family III carbohydrate-binding module from Clostridium thermocellum
}

\author{
Reinaldo Ramos, Lucília Domingues, Miguel Gama* \\ IBB - Institute for Biotechnology and Bioengineering, Centre of Biological Engineering, Universidade do Minho, Campus de Gualtar, 4710-057 Braga, Portugal
}

\section{A R T I C L E I N F O}

\section{Article history:}

Received 8 September 2009

and in revised form 20 October 2009

Available online 31 October 2009

\section{Keywords:}

Antimicrobial peptide

LL37

CBM3

Cellulose

Formic acid

\begin{abstract}
A B S T R A C T
The cathelicidin derived human peptide LL37 has a broad spectrum of antimicrobial and immunomodulatory activities. The large variety of biological activities makes LL37 a very promising candidate for clinical applications. The production of biologically active LL37 in large amounts with reduced costs can only be achieved using recombinant techniques. In this work, LL37 has been cloned to the N- and C-termini of a family III carbohydrate-binding module fused to the linker sequence (LK-CBM3) from Clostridium thermocellum; both constructions (LL37-LK-CBM3 and LK-CBM3-LL37) were cloned into the pET-21a vector. A formic acid recognition site was introduced between the two modules, allowing the isolation of LL37 after chemical cleavage.

The recombinant proteins were expressed in Escherichia coli BL21 (DE3) and solubilized with Triton X100. The purification was achieved using cellulose CF11 fibers, taking advantage of the CBM3 specific affinity for cellulose; after hydrolysis with formic acid, LL37 was further purified by reverse-phase HPLC, as confirmed by MALDI-TOF mass spectrometry. The production and purification methodology developed in this work compares advantageously to other protocols previously described, having fewer purification steps. Only the recombinant LL37 obtained from the C-terminally fused protein (LK-CBM3-LL37) showed antibacterial activity against E. coli $\mathrm{K} 12$, with a MIC of $180 \mu \mathrm{g} / \mathrm{ml}$.
\end{abstract}

(c) 2009 Elsevier Inc. All rights reserved.

\section{Introduction}

The increasing resistance of microorganisms against common antibiotics has become a growing threat for the public health. Antimicrobial peptides (AMPs) ${ }^{1}$ are part of the innate immune system and have a large spectrum of antimicrobial activities against Grampositive and Gram-negative bacteria, fungi [1] and viruses [2]. AMPs are generally defined as cationic, amphipathic peptides, with less than 50 amino acids, including multiple arginine and lysine residues [3] and show inhibitory concentrations (MIC) as low as $0.25-4 \mu \mathrm{g} / \mathrm{ml}[2]$. They are widely distributed in nature, from insects to plants and animal species; over 1440 AMPs have been identified so far (http://aps.unmc.edu/AP/main.php; July 2009).

In mammals, defensins and cathelicidins represent the two major types of AMPs. Cathelicidins share a highly conserved N-terminal cathelin domain, flanked by a rather variable antimicrobial peptide on the C-terminus [4]. The hCAP-18/LL37 is the only human cathelicidin. The antimicrobial peptide is referred to as LL37,

\footnotetext{
* Corresponding author. Fax: +351253678986.

E-mail address: fmgama@deb.uminho.pt (M. Gama).

1 Abbreviations used: AMPs, antimicrobial peptides; CBM, carbohydrate-binding module; CBD, cellulose binding domain; PCR, polymerase chain reaction; TFA, trifluoroacetic acid; MIC, minimal inhibitory concentration.
}

since it has a 37 amino acids sequence starting with two leucines. It is a $4.5 \mathrm{kDa}$, cationic (+6), amphipathic $\alpha$-helical peptide, with a broad spectrum of antimicrobial activity. LL37 and the precursor protein, hCAP-18, can be found at different concentrations in many different cells, tissues and body fluids. Durr et al. [5] summarized the various tissues where LL37 expression has been detected. Besides its protective effect against infections, a variety of other biological activities have been described. In fact, LL37 induces chemotaxis of mast cells [6], monocytes, T lymphocytes and neutrophils [7], promotes wound healing [8], angiogenesis and arteriogenesis [9].

Many bacterial and fungal enzymes that hydrolyse insoluble carbohydrates share a common structure composed of a catalytic domain linked to a carbohydrate-binding module (CBM). CBMs that are specific for insoluble cellulose (cellulose binding domain - CBD) represent the predominant category. The CBMs can be grouped into distinctive families on the basis of amino acid sequence similarities [10]; 53 families of CBMs have been recognized so far (http://www.cazy.org/fam/acc_CBM.html; July 2009).

Family III CBDs normally comprise $\sim 150$ amino acids residues, have been identified in many different bacterial enzymes, and also in non-hydrolytic proteins [11]. Clostridium thermocellum produces a multi-enzyme complex of cellulases and hemicellulases, termed the cellulosome, which is assembled by the scaffoldin protein CipA. 
Binding of the cellulosome to the plant cell wall is driven by the action of the CipA family 3 CBM (CBM3), which presents high affinity for crystalline cellulose [12]. CBM3 belongs to the all- $\beta$ family of proteins and is arranged in two antiparallel $\beta$ sheets that form a $\beta$ sandwich with jellyroll topology [11].

In this work, we describe the successful cloning, expression and purification of LL37 using the CBM3 from C. thermocellum as fusion partner. The CBM3 is overexpressed in Escherichia coli and it is possible to take advantage of its affinity properties to purify recombinant proteins on cellulose fibers, reducing significantly the costs of purification.

\section{Materials and methods}

\section{Construction of expression vectors}

The gene encoding CBM3 fused to the endogenous CipA N-terminal linker sequence (LK) has previously been cloned in the expression vector pET21-a (Novagen), in our laboratory [12]. Here, two expression vectors were constructed with LL37, either at the $\mathrm{N}$-terminus (LL37-LK-CBM3) or C-terminus (LK-CBM3-LL37) of the pET21-LK-CBM3 vector (Fig. 1).

The DNA fragment encoding LL37 was amplified by polymerase chain reaction (PCR) from hCAP-18/pET15b generously provided by Dr. Ole Sorensen, Lund University, Lund, Sweden. For the LL37-LK-CBM3 construction, the following primers were used: $5^{\prime}$ GGA ATTC CAT ATG CTG CTG GGT GAT TTC TTC-3' (forward primer) and 5'-CTA GCT AGC CGG ATC GGA CTC TGT CCT GGG TAC-3' (reverse primer). For the LK-CBM3-LL37 construction, the primers were: 5'-CCG CTC GAG GAT CCG CTG CTG GGT GAT TTC TTC-3' (forward primer) and $5^{\prime}$-CCG CTC GAG TTA GGA CTC TGT CCT GGG TAC-3' (reverse primer). NdeI, NheI (LL37-LK-CBM3) and XhoI (LK-CBM3-LL37) recognition sites are shown in bold. In order to allow the chemical cleavage with formic acid, proline and aspartate residues were introduced (in italic). PCRs were performed using the DNA Polymerase VENT (Stratagene). The PCRs were performed as follows: preheating at $95^{\circ} \mathrm{C}$ for $2 \mathrm{~min}, 30$ cycles at $95^{\circ} \mathrm{C}$ for $30 \mathrm{~s}$, $30 \mathrm{~s}$ at $52^{\circ} \mathrm{C}$ and $30 \mathrm{~s}$ at $72{ }^{\circ} \mathrm{C}$, followed by a final elongation stage at $72{ }^{\circ} \mathrm{C}$ for $10 \mathrm{~min}$. The amplified products were recovered from $1 \%$ agarose gel, digested with $\mathrm{NdeI}$ and $\mathrm{NheI}$ or $\mathrm{XhoI}$ and ligated into pET21-LK-CBM3 plasmid and sequenced to ensure that no mutations had occurred during the PCR. Fig. 1 represents LL37LK-CBM3 and LK-CBM3-LL37 constructions. The construction LL37-LK-CBM3 kept the C-terminal His6-tag even though this tag was not used for purification.

\section{Expression and purification of fusion proteins}

Fig. 2 summarizes the strategy followed for the production and purification of recombinant LL37. The recombinant plasmids were transformed into the E. coli strain BL21 (DE3) (Novagen) for protein expression. The bacterial strains were grown in Luria-Bertani

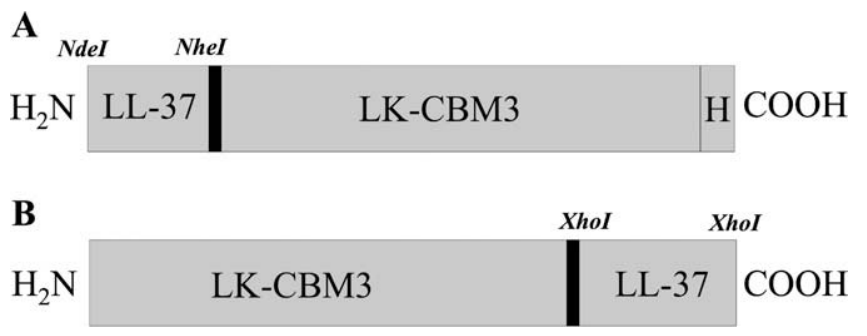

Fig. 1. Schematic representation of LL37-LK-CBM3 (A) and LK-CBM3-LL37 (B) constructions. The AspPro site for chemical cleavage with formic acid is shown in black; H, His-tag.
E. coli

Step 1: Triton X-100

Centrifugation

\section{Step 2: Fusion Protein Purification} (cellulose CF11)

\author{
Step 3: Peptide Purification \\ (RP-HPLC)
}

Formic acid cleavage

Fig. 2. Flow chart for the expression and purification of LL37 from E. coli.

broth (LB) containing $100 \mu \mathrm{g} / \mathrm{ml}$ of ampicillin at $37^{\circ} \mathrm{C}$ to mid-exponential phase $\left(\mathrm{OD}_{595}=0.6\right)$. Expression of the fusion proteins was initiated by adding isopropyl- $\beta$-D-thiogalactopyranoside (IPTG) at a final concentration of $1 \mathrm{mM}$ and the culture was incubated overnight at $37{ }^{\circ} \mathrm{C}$. The cells were centrifuged at $6000 \mathrm{rpm}$ for $15 \mathrm{~min}$ at $4{ }^{\circ} \mathrm{C}$, resuspended in Tris- $\mathrm{HCl} \mathrm{pH} 7.0,20 \mathrm{mM} \mathrm{NaCl}, 5 \mathrm{mM} \mathrm{CaCl}_{2}(2$ $\mathrm{H}_{2} \mathrm{O}$ ) buffer (CBM buffer) and sonicated in ice for $6 \mathrm{~min}$. After centrifugation at $12,000 \mathrm{rpm}$, for $30 \mathrm{~min}$ at $4{ }^{\circ} \mathrm{C}$, the cells were resuspended in CBM buffer with $1 \%$ Triton $\mathrm{X}-100$. The cells were centrifuged again at $12,000 \mathrm{rpm}$, for $30 \mathrm{~min}$ at $4{ }^{\circ} \mathrm{C}$ and the soluble fraction was collected.

The recombinant proteins were purified on cellulose CF11 (Sigma), exploiting the CBM3 cellulose-binding properties, as follows: $20 \mathrm{ml}$ of cell-free extracts were mixed with $2 \mathrm{~g}$ of cellulose and incubated, with agitation, for $1 \mathrm{~h}$ at $4{ }^{\circ} \mathrm{C}$. The cellulose with bound proteins was then centrifuged and washed five times with CBM buffer.

\section{Formic acid cleavage and LL37 purification}

In order to cleave LL37 of the recombinant protein, a 50\% formic acid solution ( $20 \mathrm{ml}$ of distilled water and $26 \mathrm{ml} 88 \%$ formic acid) was applied directly to cellulose with the adsorbed fusion proteins. The mixture was then incubated for $24 \mathrm{~h}$ at $50{ }^{\circ} \mathrm{C}$. The supernatant was separated after centrifugation at $12,000 \mathrm{rpm}$, for $30 \mathrm{~min}$, and lyophilized to remove formic acid. The cleavage was confirmed by SDS-PAGE using a $16.5 \%$ Tris-Tricine gel.

The purification of LL37 was achieved by reverse-phase HPLC, using an YMC C18 preparative column $(250 \times 30 \mathrm{~mm})$ equilibrated with aqueous acetonitrile (5\%)/0.1\% trifluoroacetic acid (TFA). The peptide was eluted using a linear gradient of acetonitrile from $5 \%$ to $90 \%$ at a flow rate of $5 \mathrm{ml} / \mathrm{min}$. The elution was monitored at $215 \mathrm{~nm}$. Several peaks were collected and analyzed by SDS-PAGE using a $16 \%$ Tris-Tricine gel. The fraction corresponding to pure LL37 was lyophilized. The concentration of the recombinant peptides was quantified using Waddell's method [13].

\section{MALDI-TOF mass spectrometry}

The purity of LL37 was confirmed by mass spectrometry at the Institute of Molecular Pathology and Immunology of the University 
of Porto (IPATIMUP). Samples were desalted and concentrated using microC18 ZipTips (Millipore, USA) accordingly to the manufacturer's protocol. The samples were eluted with the matrix $\alpha$-cyano-4-hydroxycinnamic acid (5 mg/mL) in 50\% acetonitrile/0.1\% TFA and spotted onto a stainless steel 192-well MALDI plate. After sample crystallization, mass spectrum acquisition was performed using a 4700 Proteomics Analyzer MALDI-TOF/TOF (Applied Biosystems, USA). Mass spectra were acquired in positive linear mode for $1-15 \mathrm{kDa}(\mathrm{m} / \mathrm{z})$ mass window and in positive reflector mode for the ranges 700-7000, 4000-5000 and 4585-4600 Da $(\mathrm{m} / \mathrm{z})$. External calibration of the mass spectrum was performed using Applied Biosystems Calibration Mix 3 standards.

\section{Antibacterial activity}

The antibacterial activity of the pure peptides was quantified in 96-well polypropylene microtiter plates, as described by Vogt and Bechinger [14], with some modifications. E. coli strain K12 was grown at $37^{\circ} \mathrm{C}$ in LB medium until mid-logarithmic phase $\left(\mathrm{OD}_{600}=0.5\right)$. The cells were then resuspended in LB at $1 \times 10^{6}$ and $1 \times 10^{5}$ cells $/ \mathrm{ml} ; 100 \mu \mathrm{l}$ of peptides, at different concentrations, were inoculated with $50 \mu \mathrm{l}$ of bacterial suspension, incubated overnight at $37^{\circ} \mathrm{C}$ and the bacterial growth was assessed by the measurement of optical density at $620 \mathrm{~nm}$. The results were confirmed by plating $25 \mu \mathrm{l}$ aliquots of the mixture from each well in LB plates and incubating for $16 \mathrm{~h}$ at $37^{\circ} \mathrm{C}$, followed by colony counting. Each assay was repeated three times and controls were made by adding sterile deionized water, instead of the peptide solutions. The minimal inhibitory concentration (MIC) was determined as the lowest peptide concentration that inhibited bacterial growth.

\section{Results and discussion}

\section{Expression and purification of recombinant proteins}

The protein LL37 was successfully cloned at both the N- and Cterminus of the LK-CBM3 in the expression vector pET21-a. After transformation of the recombinant plasmids into E. coli BL21 (DE3), several fermentation conditions were tested, attempting to optimize the production of the recombinant proteins in the soluble form. The following operational parameters and E. coli strains were varied or tested: concentration of IPTG, induction temperature and

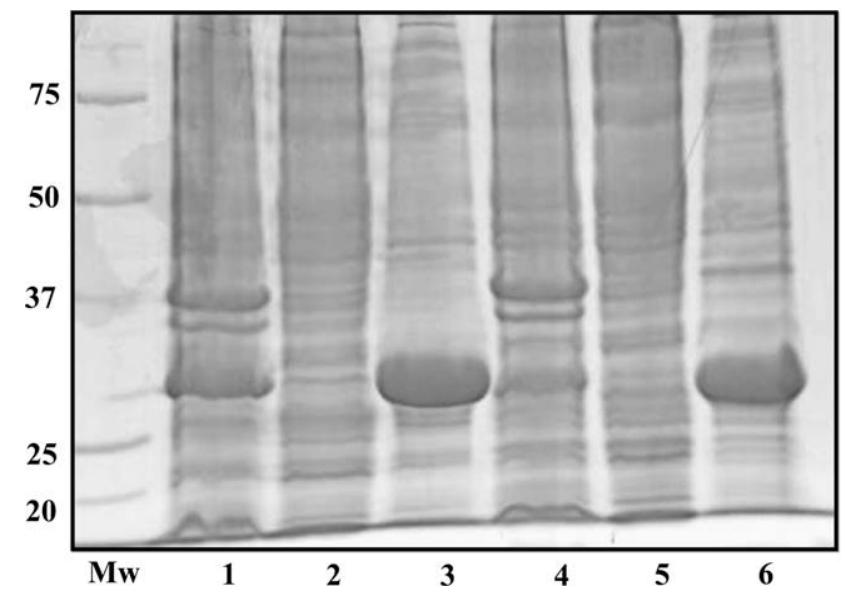

Fig. 3. Expression of recombinant proteins LL37-LK-CBM3 and LK-CBM3-LL37. $M_{\mathrm{w}}$, protein molecular weight marker; 1, LL37-LK-CBM3 insoluble fraction; 2, LL37-LKCBM3 soluble fraction; 3, LL37-LK-CBM3 Triton X-100 solubilized fraction; 4, LKCBM3-LL37 insoluble fraction; 5, LK-CBM3-LL37 soluble fraction; 6, LK-CBM3-LL37 Triton X-100 solubilized fraction.

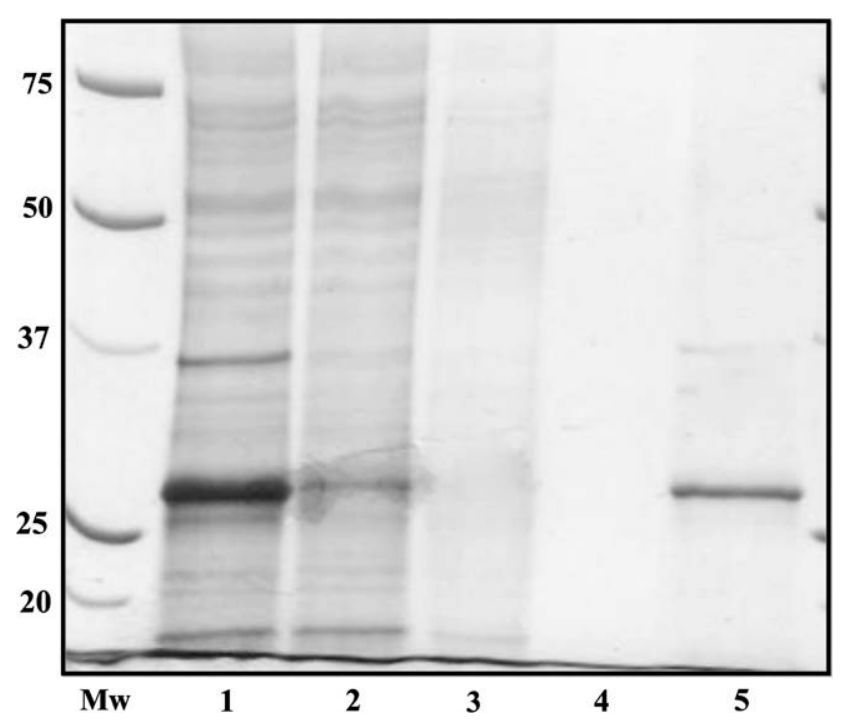

Fig. 4. Binding assay of LK-CBM3-LL37 on CF11 fibers. $M_{\mathrm{w}}$, protein molecular weight marker; 1 , Triton solubilized supernatant; 2 , unbound protein; 3 , first cellulose wash; 4 , fifth cellulose wash; 5 , bound protein eluted with $1 \%$ SDS.

time, fermentation in M9 minimal medium, transformation into E. coli Tuner (DE3) and Origami (DE3) and co-expression with chaperones GroEL-GroES and E. coli trigger factor (TF) [15]. Only using the nonionic detergent, Triton $\mathrm{X}-100$, the production of the proteins $(\sim 27 \mathrm{kDa})$ in the soluble form was achieved (Fig. 3).

In previous work, Guerreiro et al. [12] reported the expression of the same CBM3 from $C$. thermocellum used in this work. The CBM, fused or not with small antimicrobial peptides, was overexpressed in the soluble form. Only the protein LKLLKKLLKLLKKLGGGK-LKCBM3 was found to be insoluble when expressed by different E. coli strains, under a range of induction conditions. In this work, the CBM3 fused to LL37 could only be solubilized with detergents. The use of CBM3 as fusion partner had two major goals: (1) to express and purify the peptide LL37 by a novel, fast and inexpensive method, using cellulose for purification and (2) to modify the surface of cotton fabrics with LL37, aiming at obtaining textiles with antibacterial and bioactive properties. As already stated, LL37 is an antimicrobial peptide but it also has a broad spectrum of biological activities. Thus, one main objective was to modify cellulose for biomedical applications. However, in this work, we focus on the production of the isolated LL37. For this purpose, the CBM is still useful,

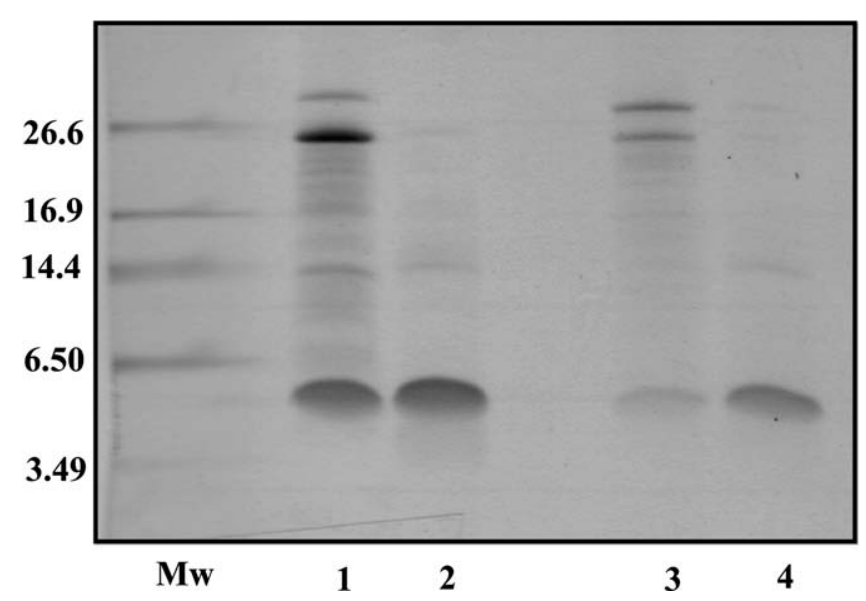

Fig. 5. Formic acid cleavage and release of LL37. $M_{\mathrm{w}}$, protein molecular weight marker; 1, insoluble fraction of cleaved LL37-LK-CBM3; 2, supernatant of cleaved LL37-LK-CBM3; 3, insoluble fraction of cleaved LK-CBM3-LL37; 4, supernatant of cleaved LK-CBM3-LL37. 

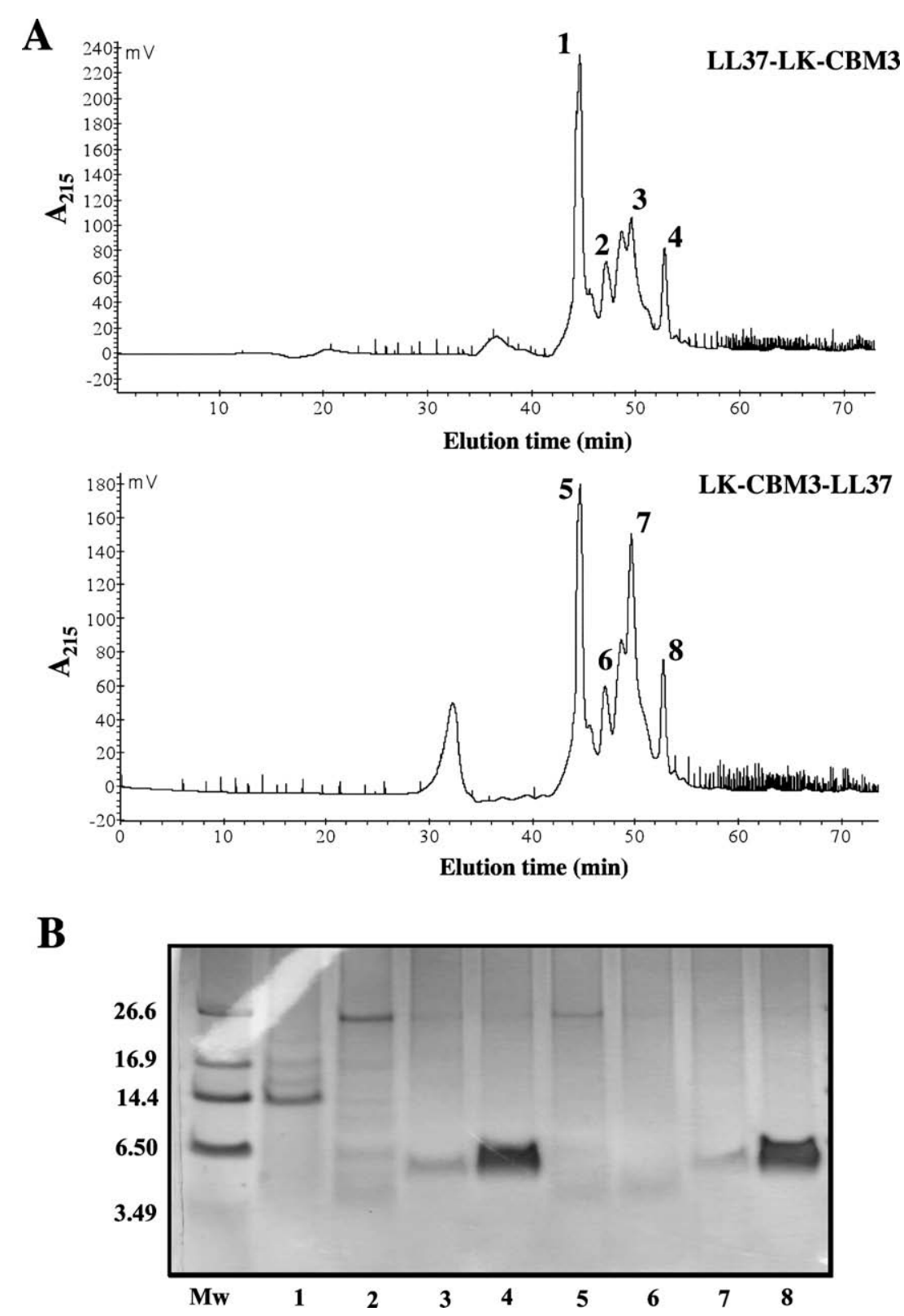

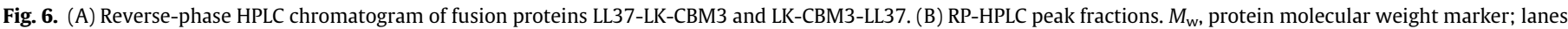
1-4, peak fractions of cleaved LL37-LK-CBM3; lanes 5-8, peak fractions of cleaved LK-CBM3-LL37.

allowing the separation of the recombinant protein through inexpensive affinity-based separation, using cellulose fibers.

The purification of the LL37-LK-CBM3 and LK-CBM3-LL37 recombinant proteins was performed on cellulose CF11 fibers. The family III CBM from $C$. thermocellum is well studied. This CBM adsorbs to cellulose with high affinity constants [16]. The fusion with LL37 and the presence of residual detergent did not affect the binding of the CBM3 on CF11 cellulose. Fig. 4 shows a binding assay of the LK-CBM3-LL37 recombinant protein, performed as described previously [12]. The recombinant proteins bind very efficiently to cellulose and only desorb using SDS.

To date, few groups have reported the recombinant expression of LL37 either in the E. coli expression system [17-19] or in the Pichia pastoris system [20]. In these publications, the purification of the recombinant proteins is always performed through affinity chromatography techniques, using expensive matrixes (sepharose, cobalt). Although very effective, chromatography is a slow process with high costs. LL37 is a peptide with a large potential for biomed- ical applications. Thus, the production of large amounts of LL37 at low costs is of great importance, purification being generally the most critical step in this regard. Cellulose is cheap and available in many forms. Therefore, the expression system using the CBM3 as the expression and purification module is very attractive. As shown previously [12] and in this work, the CBM3, when fused to antimicrobial peptides, is overexpressed in E. coli conserving its binding properties. The adsorption of CBM3 on cellulose is quite fast, allowing the recombinant proteins to be purified in a quick, inexpensive method. Moreover, no columns and chromatography units are required. Compared with previous publications, this method is clearly the best for large-scale purification of LL37.

\section{Chemical cleavage and purification of LL37}

Several methods, both enzymatic (factor Xa and thrombin proteases) and chemical ( $\mathrm{CNBr}$ and formic acid) are widely used to cleave proteins from fusion partners. Formic acid is a good option 

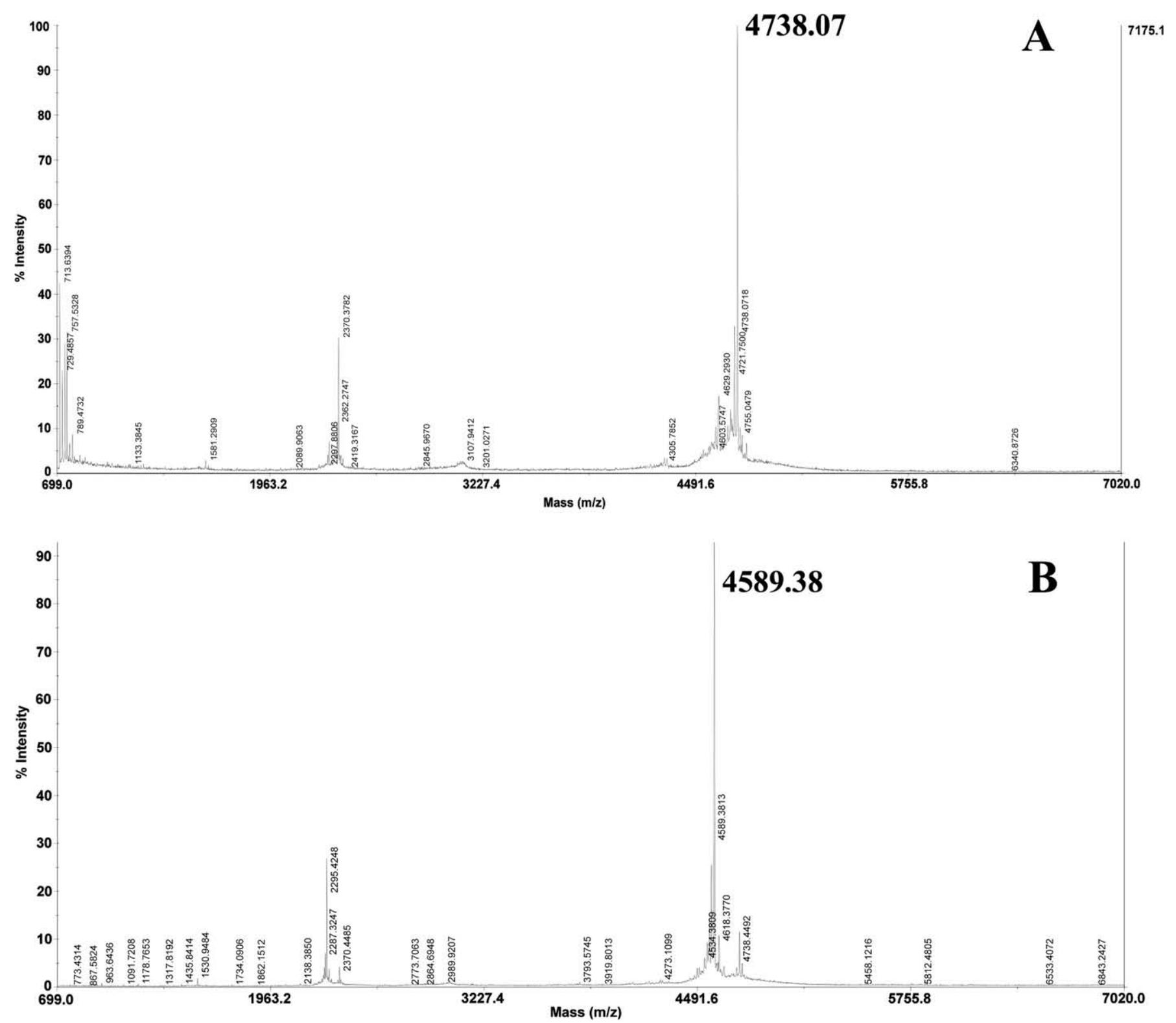

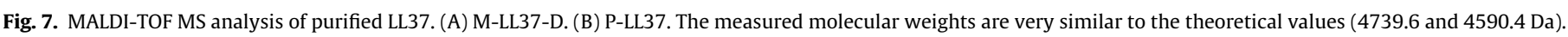

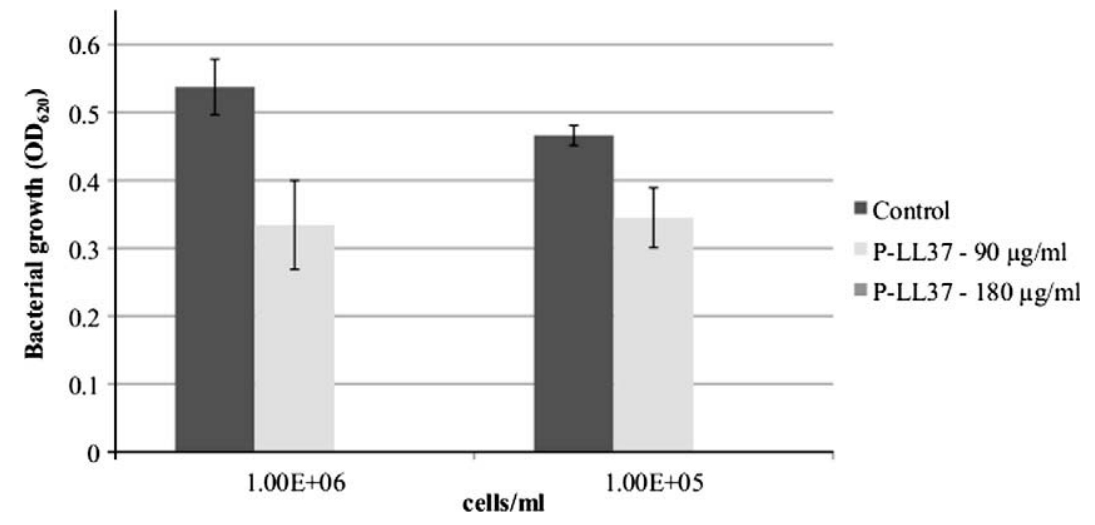

Fig. 8. Antibacterial activity of P-LL37 against E. coli K12. Bacterial growth was inhibited at a concentration of $180 \mu \mathrm{g} / \mathrm{ml}$ of P-LL37.

for large-scale production, due to its low cost. The chemical cleavage of the recombinant proteins was performed, in this work, with $50 \%$ formic acid, at $50{ }^{\circ} \mathrm{C}$ for $24 \mathrm{~h}$. LL37-LK-CBM3 and LK-CBM3-
LL37 proteins were first purified on cellulose. Then, formic acid was applied directly on the CF11 fibers with the bound protein. After centrifugation, the supernatants were lyophilized to 
completely remove the acid and analyzed by $16.5 \%$ Tris-Tricine gel (Fig. 5). After acid hydrolysis and lyophilization, part of the protein (mostly CBM) precipitates, probably degraded by the formic acid. On the other hand, most of the peptide $(\sim 4.5 \mathrm{kDa})$ remains soluble, as shown in Fig. 5 (lanes 2 and 4). The precipitation of the CBM3 facilitates the purification. In fact, LL37 is separated from most of the CBM and other contaminating proteins by centrifugation. The soluble supernatants, with a large proportion of LL37, were then subjected to RP-HPLC to achieve higher purity (Fig. 6a). In this step, the fractions corresponding to the major peaks were collected and the purity of the peptides was checked on $16.5 \%$ Tris-Tricine gel and confirmed by MALDI-TOF. Fig. 6b presents the peak fractions from RP-HPLC for the two fusion proteins. Lanes 4 and 8 demonstrate the purity of the two peptides.

The two different proteins, both including the LL37, were obtained after the formic acid cleavage of the CBM constructs. The first peptide, obtained by the cleavage of the LL37-LK-CBM3 protein, has 39 amino acids with a theoretical molecular weight of 4739.6 Da. It is flanked with the N-terminal methionine, remaining from the translation process and a C-terminal aspartic acid, left by the chemical cleavage (M-LL37-D). Although 55-70\% of mature proteins are subjected to N-terminal Met excision [21], M-LL37-D conserved the initial amino acid. Indeed, as demonstrated by Sherman et al. [22] most proteins retain the initial Met when the N-terminus residue is leucine. The second peptide, cleaved from the LKCBM3-LL37 protein, is 38 amino acids long, with a theoretical molecular weight of $4590.4 \mathrm{Da}$, having a proline residue at the $\mathrm{N}$ terminus (P-LL37). Mass spectrometry (Fig. 7) confirmed the purity of LL37 and the predicted molecular weights.

The production and purification of LL37 using CBM3 as the fusion partner only requires one chromatographic step. All previous publications refer to at least two, and use enzymes to cleave LL37. Li et al. [17,23] also use formic acid for chemical release of LL37, however the purification scheme used is more complex. In this work, it was possible to obtain $1 \mathrm{mg}$ of pure P-LL37 and $2 \mathrm{mg}$ of pure M-LL37-D from $1 \mathrm{~L}$ of bacterial culture. This yield is comparable to the ones obtained in previous studies [17-19]. Li et al. [23] also described a novel method to purify LL37 utilizing its property of aggregation. The authors were able to produce $2.6 \mathrm{mg}$ of recombinant LL37 from $1 \mathrm{~L}$ of culture. However, this method required two cleavage steps with thrombin and formic acid and three purification steps.

\section{Antibacterial activity}

M-LL37-D and P-LL37 antibacterial activities were tested against $E$. coli $\mathrm{K} 12$. The concentration of the peptides was quantified by UV spectroscopy using the Waddell's method [13]. Fig. 8 demonstrates that P-LL37 has antimicrobial activity, with a MIC of about $180 \mu \mathrm{g} / \mathrm{ml}(40 \mu \mathrm{M})$, similar to the values found in the literature [5,17]. At lower concentration, P-LL37 inhibited bacterial growth only partially. The peptide (M-LL37-D) obtained from the N-terminal fusion construct (LL37-LK-CBM3) showed no antibacterial activity. According to Nagaoka et al. [24], the N-terminus and C-terminus of LL37 do not contribute to the formation of $\alpha$-helical structures, being less important for its antimicrobial activity. However, the C-terminal aspartic acid reduces the global charge of the peptide. Furthermore, Giglione et al. [21] suggest that an N-terminal Met may act as a destabilization signal. This peptide has a total charge of +5 , so the second hypothesis seems to be more likely. In fact, other AMPs with lower net charge still exhibit antibacterial activity. As already stated, recombinant LL37 has already been expressed and purified and $E$. coli but only two groups tested the antibacterial activity of the pure peptides. Yang et al. [18] produced the peptide GSLL-39 with a MIC of $12.5 \mu \mathrm{g} / \mathrm{ml}$ against $E$. coli DH5 $\alpha$ and $25 \mu \mathrm{g} / \mathrm{ml}$ against $S$. aureus; Li et al. [17] obtained the peptide P-
LL37 with a MIC of $180 \mu \mathrm{g} / \mathrm{ml}(40 \mu \mathrm{M})$ against E. coli K12. Durr et al. [5] report that the MIC of LL37 against E. coli and S. aureus is higher than $144 \mu \mathrm{g} / \mathrm{ml}(32 \mu \mathrm{M})$, similar to the P-LL37 expressed previously and in this work (Fig. 8).

\section{Conclusions}

LL37 has been extensively studied in recent years. The variety of immunological and antimicrobial activities makes LL37 a very promising candidate for clinical applications. For these purposes, high amounts of affordable LL37 can only be obtained using recombinant techniques. Major advances in solid-phase chemical synthesis of peptides, over the last five years have rendered the largescale synthesis of long chain-length bioactive peptides possible, but this technique is too expensive for the production of large quantities of pure peptides with more than 30 amino acids. In this work, the family III CBM from $C$. thermocellum was used as fusion partner, taking advantage of its cellulose-binding properties for purification. The antibacterial assays showed that only P-LL37 was active. The methodology described in this work appears to be very effective for production and purification of AMPs. The use of cellulose for purification and formic acid for chemical cleavage make this method the more cost effective when comparing to previous publications.

\section{Acknowledgments}

This work was supported by the individual Grant SFRH/BD/ 27404/2006 from Fundação para a Ciência e a Tecnologia (Portugal). We are grateful to Prof. Ole Sorensen at the Lund University, Sweden. The authors acknowledge Dr. Hugo Osório and the IPATIMUP Proteomics Unit at the Institute of Molecular Pathology and Immunology of the University of Porto (IPATIMUP) for the MALDI-TOF spectrometry analysis of the peptides.

\section{References}

[1] K. Ajesh, K. Sreejith, Peptide antibiotics: an alternative and effective antimicrobial strategy to circumvent fungal infections, Peptides 30 (2009) 999-1006.

[2] R.E. Hancock, G. Diamond, The role of cationic antimicrobial peptides in innate host defences, Trends Microbiol. 8 (2000) 402-410.

[3] J.P.S. Powers, R.E.W. Hancock, The relationship between peptide structure and antibacterial activity, Peptides 24 (2003) 1681-1691.

[4] B. Ramanathan, E.G. Davis, C.R. Ross, F. Blecha, Cathelicidins: microbicidal activity, mechanisms of action, and roles in innate immunity, Microbes Infect. 4 (2002) 361-372.

[5] U.H. Durr, U.S. Sudheendra, A. Ramamoorthy, LL-37, the only human member of the cathelicidin family of antimicrobial peptides, Biochim. Biophys. Acta 1758 (2006) 1408-1425.

[6] F. Niyonsaba, K. Iwabuchi, A. Someya, M. Hirata, H. Matsuda, H. Ogawa, I. Nagaoka, A cathelicidin family of human antibacterial peptide LL-37 induces mast cell chemotaxis, Immunology 106 (2002) 20-26.

[7] D. Yang, Q. Chen, A.P. Schmidt, G.M. Anderson, J.M. Wang, J. Wooters, J.J Oppenheim, O. Chertov, LL-37, the neutrophil granule- and epithelial cellderived cathelicidin, utilizes formyl peptide receptor-like 1 (FPRL1) as a receptor to chemoattract human peripheral blood neutrophils, monocytes, and T cells, J. Exp. Med. 192 (2000) 1069-1074.

[8] J.D. Heilborn, M.F. Nilsson, G. Kratz, G. Weber, O. Sorensen, N. Borregaard, M. Stahle-Backdahl, The cathelicidin anti-microbial peptide LL-37 is involved in re-epithelialization of human skin wounds and is lacking in chronic ulcer epithelium, J. Invest. Dermatol. 120 (2003) 379-389.

[9] R. Koczulla, G. von Degenfeld, C. Kupatt, F. Krotz, S. Zahler, T. Gloe, K. Issbruicker, P. Unterberger, M. Zaiou, C. Lebherz, A. Karl, P. Raake, A. Pfosser, P. Boekstegers, U. Welsch, P.S. Hiemstra, C. Vogelmeier, R.L. Gallo, M. Clauss, R. Bals, An angiogenic role for the human peptide antibiotic LL-37/hCAP-18, J. Clin. Invest. 111 (2003) 1665-1672.

[10] N.R. Gilkes, B. Henrissat, D.G. Kilburn, R.C. Miller Jr., R.A. Warren, Domains in microbial beta-1,4-glycanases: sequence conservation, function, and enzyme families, Microbiol. Rev. 55 (1991) 303-315.

[11] J. Tormo, R. Lamed, A.J. Chirino, E. Morag, E.A. Bayer, Y. Shoham, T.A. Steitz Crystal structure of a bacterial family-III cellulose-binding domain: a general mechanism for attachment to cellulose, EMBO J. 15 (1996) 5739-5751.

[12] C.I. Guerreiro, C.M. Fontes, M. Gama, L. Domingues, Escherichia coli expression and purification of four antimicrobial peptides fused to a family 3 
carbohydrate-binding module (CBM) from Clostridium thermocellum, Protein Expr. Purif. 59 (2008) 161-168.

[13] W.J. Waddell, A simple ultraviolet spectrophotometric method for the determination of protein, J. Lab. Clin. Med. 48 (1956) 311-314.

[14] T.C.B. Vogt, B. Bechinger, The interactions of histidine-containing amphipathic helical peptide antibiotics with lipid bilayers - the effects of charges and $\mathrm{pH}, \mathrm{J}$. Biol. Chem. 274 (1999) 29115-29121.

[15] K. Nishihara, M. Kanemori, H. Yanagi, T. Yura, Overexpression of trigger factor prevents aggregation of recombinant proteins in Escherichia coli, Appl. Environ. Microbiol. 66 (2000) 884-889.

[16] P. Tomme, A. Boraston, B. McLean, J. Kormos, A.L. Creagh, K. Sturch, N.R. Gilkes, C.A. Haynes, R.A.J. Warren, D.G. Kilburn, Characterization and affinity applications of cellulose-binding domains, J. Chromatogr. B Biomed. Sci. Appl. 715 (1998) 283-296.

[17] Y. Li, X. Li, G. Wang, Cloning, expression, isotope labeling, and purification of human antimicrobial peptide LL-37 in Escherichia coli for NMR studies, Protein Expr. Purif. 47 (2006) 498-505.

[18] Y.H. Yang, G.G. Zheng, G. Li, X.J. Zhang, Z.Y. Cao, Q. Rao, K.F. Wu, Expression of bioactive recombinant GSLL-39, a variant of human antimicrobial peptide LL37 in Escherichia coli, Protein Expr. Purif. 37 (2004) 229-235.
[19] J.Y. Moon, K.A. Henzler-Wildman, A. Ramamoorthy, Expression and purification of a recombinant LL-37 from Escherichia coli, Biochim. Biophys. Acta 1758 (2006) 1351-1358.

[20] I.P. Hong, S.J. Lee, Y.S. Kim, S.G. Choi, Recombinant expression of human cathelicidin (hCAP18/LL-37) in Pichia pastoris, Biotechnol. Lett. 29 (2007) 7378.

[21] C. Giglione, A. Boularot, T. Meinnel, Protein N-terminal methionine excision, Cell. Mol. Life Sci. 61 (2004) 1455-1474.

[22] F. Sherman, J.W. Stewart, S. Tsunasawa, Methionine or not methionine at the beginning of a protein, Bioessays 3 (1985) 27-31.

[23] Y. Li, X. Li, H. Li, O. Lockridge, G. Wang, A novel method for purifying recombinant human host defense cathelicidin LL-37 by utilizing its inherent property of aggregation, Protein Expr. Purif. 54 (2007) 157-165.

[24] I. Nagaoka, S. Hirota, F. Niyonsaba, M. Hirata, Y. Adachi, H. Tamura, S. Tanaka, D. Heumann, Augmentation of the lipopolysaccharide-neutralizing activities of human cathelicidin CAP18/LL-37-derived antimicrobial peptides by replacement with hydrophobic and cationic amino acid residues, Clin. Diagn. Lab. Immunol. 9 (2002) 972-982. 